\title{
Distance learning during the pandemic: managing the challenges
}

\author{
Elena Rudenko, ${ }^{1,}$, Rupiya Bachieva $^{2}$, Alfiya Aligadzhieva ${ }^{3}$, Zarema Temirhanova ${ }^{3}$, and Atikat \\ Archilaeva ${ }^{3}$ \\ ${ }^{1}$ Don State Technical University, 344003, Gagarin Square, 1, Rostov-on-Don, Russia \\ ${ }^{2}$ Rostov State University of Economics (RINH), 344002, Bolshaya Sadovaya str., 69, Rostov-on-Don, \\ Russia \\ ${ }^{3}$ Dagestan State Technical University, Imam Shamil avenue, 367015, 70, Makhachkala, Republic of \\ Dagestan, Russia
}

\begin{abstract}
This study examined educational challenges related to teaching online at universities that have surfaced during the COVID-19 outbreak. The authors explicate the main issues pertaining to online teaching and learning in general and foreign languages teaching in particular. The article sets out to address the following challenges for educators using information and communication technology: handling a wide variety of online learning platforms and learning apps, adapting courses to a fully online environment and increasing students' engagement. Finally, the article identifies strategies and techniques for reducing or eliminating these issues for students and academic staff. The objectives set have been achieved by means of general methods of scientific knowledge (observation, analysis and synthesis) and reflective methods. The authors conclude that there should be a strong emphasis on a comprehensive approach to support students and academic staff in online learning environment. The results and implications of this study are critical for educators developing and delivering online language courses.
\end{abstract}

\section{Introduction}

The drastic changes in today's world places additional demands on the education system. A large number of universities across the world are shifting the focus from traditional education to a web-supported education that can be provided either fully online or through blended learning (hybrid learning). It has been recognized that online learning has many advantages. The chief educational advantage is that students enrolled in online courses offered in asynchronous learning environments are able to access information in a flexible way without ever leaving home [1]. Other advantages of online learning include the following: well-structured and efficient management of assignments, competitive advantage (online learning provides access to good quality education), cost effectiveness etc.

However, the results of some studies carried out on online education highlighted weaknesses in the teaching-learning process from the students ' perspective as well as from the perspective of teachers involved in online education.

\footnotetext{
${ }^{*}$ Corresponding author: RudenkoElena1988@yandex.ru
} 
There are still local problems caused by the application of Information and Communication Technology (ICT). A survey conducted by Joseph B. Umoh and Ekemini T. Akpan in 2014 among the students of the University of Uyo, Nigeria investigated challenges of blended elearning and revealed "non-availability, non-accessibility and inadequate ICT skills towards the utilization of blended e-learning tools". The authors explain these results as due to "lack of ICT infrastructures to supports blended e-learning approaches" [2]. The lack of access to the Internet at home, the lack of computer availability, slow internet connection and login problems are cited as the main obstacles to access online educational resources at the University of the Western Cape (UWC) in Cape Town [3]. Improving Internet access and enhancing ICT literacy and information literacy in the developing world is still an area of great concern [4].

Another prominent problem faced by online students is the isolation of an online course. More particularly, students experience hurdles in learning situations that involve group work and group assessments [5]. The barriers to participation can be of a personal nature: inability to build interpersonal relationships with peers, stress and anxiety states associated with using technology, being pushed out of one's comfort zone.

The importance of effective online collaboration/group work cannot be overestimated; however, potential barriers to achievement may serve to isolate the students resulting in disengagement or withdrawal.

In addition, members of the teaching staff can also have difficulties when trying to implement new ideas and practices, educators feel stressed and not equipped with the relevant skills to teach online and guide students through learning activities, especially in such cases when they themselves may be struggling to make effective use of sophisticated learning technologies [6-8].

There is a need for more adequate training of academic staff in the field of ICT-based learning environments, which will help educators do their jobs with confidence and help students reach for their maximum potential.

\section{Objectives and methods}

The focus of the current study lays on academic staff perspectives of what were the main challenges encountered during the pandemic at higher educational institutions using the example of Don State Technical University. The presentation of the results of this analysis is backed up by practical suggestions on how to manage these challenges, which is applicable not only to the emergency situation, but also to normal online classroom settings. This scope of research is unexplored because fully online distance courses, launched due to sudden coronavirus outbreak, haven't been implemented before across Russia. Hence, it should be considered valuable experience for the academic community.

The present paper aims to:

- analyse challenges that hindered the effective transition to an online learning environment (using the example of teaching English courses);

- suggest practical solutions that can be implemented to respond to challenges;

- identify the status of e-learning environment at Don State Technical University.

The objectives set have been achieved by means of general methods of scientific knowledge (observation, analysis and synthesis) and reflective methods that allow selecting effective teaching strategies that will help students to adapt academically in online learning environment.

\section{Learning challenges during the pandemic}

The COVID-19 pandemic caused rapid changes in higher education and "did not allow for careful deliberation in converting face-to-face courses to online delivery. Instead, faculty 
members worldwide were faced with placing as much information online as possible in the fastest manner, with some campuses getting a week-long hiatus for faculty to prepare course materials while others requiring literally a weekend turnaround process" [9].

It is impossible to encompass within the scope of one study the whole complex of issues that revealed themselves during the COVID-19 outbreak. Hence, this paper will focus on the following:

1. how to handle an overwhelming variety of online learning platforms and learning apps;

2. how to adapt courses to a fully online environment;

3. how to increase students' engagement.

\subsection{A wide variety of online learning platforms and learning apps}

The first issue turns out to be problematic for both students and academic staff alike: students may become easily distracted and overwhelmed by the necessity of switching between multiple apps and websites all the time and teachers may have trouble selecting an e-learning tool that aligns with their existing learning content. Moreover, going through detailed tutorials and importing learning content into the all-in-one platform may require some special knowledge and technical skills.

During the initial stage, it is highly desirable to build up a unified learning environment, thus providing a personal overview of the education (in terms of content, structure, and progress) and transparent access to course material. In addition to the mentioned benefits, a unified learning environment helps save students' time and ease teachers' workload.

The implementation of distance learning in higher education institutions during the COVID19 outbreak has shown that it is possible to cope with such complex situations provided that there is a unified learning environment and sufficient technical support available to help academic staff manage maintenance issues. Providing necessary assistance with e-learning technologies is a good administrative practice that helps ensure that courses run smoothly.

\subsubsection{The status of e-learning environment at Don State Technical University}

Almost all higher education institutions have adopted one or more Learning Management Systems (LMS) to enhance e-learning [10-11]. LMSs are web-based tools that support teaching and learning and "manage" students by keeping track of their individual performance as they move through the different phases of learning. The term "LMS" is often interchanged with virtual learning environment [12]. An effective and efficient learning management system helps instructors in designing learner-centred models for blended learning courses as well as for online interaction [13].

In a competitive higher education environment e-learning is considered to be an important means of providing a strategic competitive advantage, which is why many universities dedicate themselves to designing effective learning environments.

Don State Technical University has developed a multifunctional support system using electronic-driven technologies to improve the quality of a learning process. The importance of computer and electronic technologies is objectively obvious for a university such as DSTU, which was given the status of the flagship university of the Rostov region and is attended by more than 40, 000 students.

Don State Technical University has successfully made the transition to remote learning thanks to the use of e-learning modular support system called «SKIF», which provides a holistic online administrative and learning environment for students using remote technologies.

In DSTU's e-learning environment (LMS) different tools are put together into one application; a Moodle-based «SKIF» represents one of these tools. «SKIF» enables learning 
process automation and pedagogical customization; it allows the user to add to courses all types of digital material and meets all the requirements needed for learning management systems:

1. unified logging system;

2. adoption of modular instruments to generate the outward appearance of the interface using standard visual components;

3. group-learning techniques (collaborative learning techniques) that enable students to engage in asynchronous communication in discussion forums and chat rooms;

4. course assignments submitted by electronic means for teacher marking and followed by the assignment assessment;

5. computer-aided testing systems (the instructor may impose restrictions on the time, on the number of attempts, may add summarized feedback of the test results etc.);

6. library's wide range of digital resources available to access from anywhere.

Another helpful tool developed by Don State Technical University is an electronic attendance register called "My DSTU" that allows instructors to record students' attendance at their timetabled activities. Furthermore, this register provides entry line for specifying the title of the lesson and a URL (link) that allows students to quickly access the video conferencing tool or e-learning platform, so that students can easily join the learning activities without any delays.

DSTU's unified learning environment has proven effective in campus-based blended learning courses. However, due to the unprecedented educational disruption related to COVID19 many higher education institutions moved to online-only classes, thus replacing in-person teaching with live classes via Zoom, Discord, and Skype. In the following we consider major challenges that confront teachers trying to adapt their courses to a fully online environment using the example of teaching English courses via Zoom.

\subsection{Adapting courses to a fully online environment and increasing student engagement}

The problem of adapting courses to a fully online environment goes hand in hand with student engagement issues, as student engagement goes down in an online learning process. When teachers teach onsite, they can monitor whether the student is carrying out the assigned activity. However, in a Zoom meeting teachers cannot be sure that student's attention is focused on a particular activity particularly with student's camera turned off. Therefore, it is crucial to engage students through the proper presentation of information and create a feedback loop between teacher and student for the improvement of learning performance within an online environment. Learner-to-learner interaction is also highly desired by learners, it can play a significant role in helping students eliminate a sense of isolation. According to Florence Martin and Doris U. Bolliger, activities that enhance engagement "assist students in feeling connected and can create a dynamic sense of community" [14].

At the introductory stage of the lesson it is better to organize pair work activities by means of splitting Zoom meeting in separate sessions (breakout rooms). A brief discussion task can be used as a lead-in to a topic under consideration (for instance, in a lesson on writing emails the teacher may encourage students to ask their partners questions about emails: Do you get a lot of emails? How and when do you respond? How often do you delete an email without reading it?). If this activity is carried out with the whole class, there is danger that strong students will dominate discussion and weak students will prefer to remain silent. Using breakout rooms or chats ensure that all students simultaneously engage with a task. In addition, it will help with the initial speaking anxiety, as speaking with a peer is less stressful than speaking to a teacher in front of the whole class in the Zoom application. As a result, overall quality of student talk improves. 
Other problems the teacher might run into are of a technical nature. If students do not have course books at hand and questions are displayed on the teacher's screen, they might feel confused as screen sharing options disappear in breakout rooms and as a result they might forget questions. In order to avoid such situations, it is recommended to use Google Slides - a web-designed platform for creating rich media presentations. In fact, it enables a teacher to put together all digital curriculum materials thus facilitating retrieval of multimedia content. A teacher can share the presentation with students by using the "Share" button and copying the link or by sending the link by email beforehand (the provision made for the students who arrive late to class). The use of Google Slides ensures that students are involved in the learning process at every stage of the lesson.

After speaking activity monitoring in breakout rooms is done, a teacher should provide appropriate congruent feedback before moving on to the next stage. It may look as follows:

1. A clear question plus time to think about how to answer it, e.g. "What was one thing that surprised you a great deal about your partner? I'll give you a minute to think" or "What was one thing you disagreed with?"

2. Giving nonverbal feedback. If students' cameras are turned on, a teacher can give them nonverbal ways to express their opinions: "So, do you check and respond to e-mail only at specific times? Show me your thumbs!"

3. Writing down some of the students' ideas in the course of monitoring student performance in breakout rooms and giving feedback by asking a clear question, e.g. "So here are some of the ideas I've heard. Did you discuss something else that I didn't hear?" or "So here are some of the problems you talked about. Use the annotate function in Zoom and tick the problems you've experienced".

All procedures mentioned above contribute to students' awareness of learning issues and help them stay focused and engaged in the activity.

In the main part of the lesson it makes sense to continue using Google slides, as it may serve (depending upon language skills students need to develop) as an interactive student's copybook. The teacher can duplicate the slide containing the task (like putting text segments into the correct sequence to focus on the structure of emails) and then assign each pair of students a slide name. Students can do the task and then do a "gallery walk" looking at other students' slides and leaving comments.

Google slides is also a useful tool for doing drag-and-drop exercises (e.g. sentence-topicture and sentence-to-word matching tasks at the stage of controlled practice managed by the teacher), it allows users to insert images, text boxes, and shapes, which enables students to work collaboratively on drag-and-drop tasks in a single digital information environment.

Google slides prove to be efficient in handling reading comprehension lessons, as it allows students to highlight segments of text that illustrate evidence to justify students' responses. It improves student engagement as a teacher gets students reading a text carefully, not just selecting one letter from answer choices. 
When dealing with listening it would be advisable to use Google Sheets as they allow the document to be shared with other users. Each student has a column assigned by the teacher so

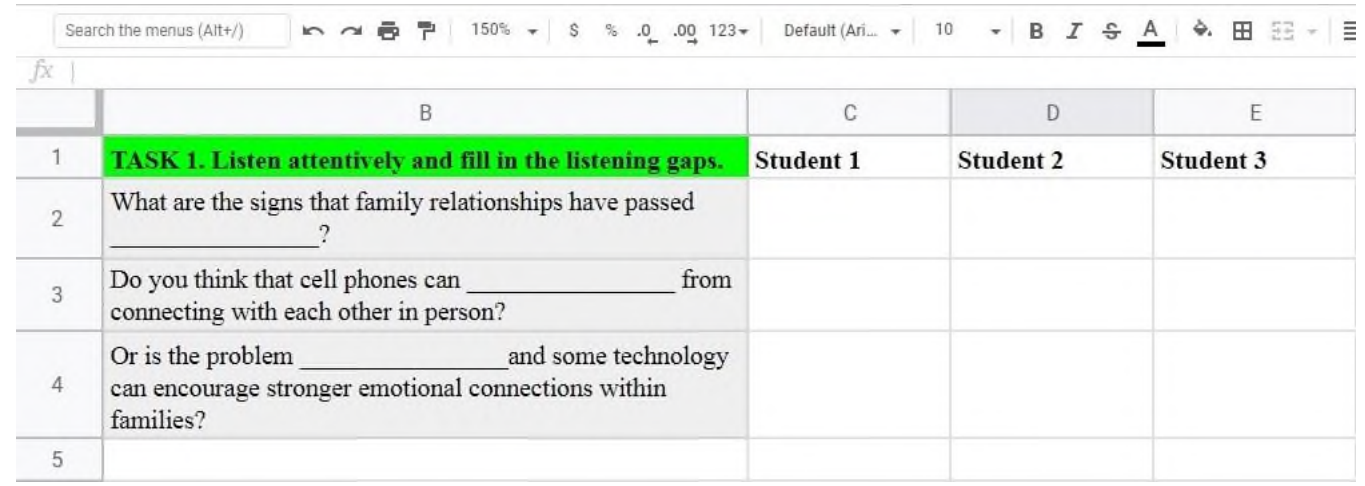

that they can collaborate on the same task simultaneously. Moreover, students will not be able to copy other students' answers as long as they type in their answers and remain in a selected cell(a teacher should give clear task instructions beforehand). As soon as students leave the cell, their answers are visible to others. Here is an example of what this activity can look like:

Fig. 1. Listening using Google Sheets

Whatever learning activity students are engaged in, it is wise for the teacher to prepare supplementary activities or additional resources that will keep the early finishers from wasting their extra time in the Zoom application. For instance, a teacher can draw a text box in the lower-right corner of the slide to assign silent follow-up activities for fast-finishers.Through thoughtful classroom design, teachers can maximize the satisfaction from the time spent in the online classroom, which in turn will support students' holistic learning experiences [15].

Creating a successful online class and a sense of community in the online classroom is a labour and time intensive task which requires a significant amount of specialized knowledge. Online teaching staff should constantly rise to practical challenges of implementing online classes and programs to find new ways to promote meaningful interactions between students.

\section{Conclusions}

The COVID-19 outbreak brought many challenges, including moving courses online, but it also provided educators with the opportunity to try new teaching strategies using tools available online.

In the present paper we have identified the following issues that revealed themselves during the COVID-19 outbreak: a wide variety of online learning platforms and learning apps, difficulty of adapting courses to a fully online environment and increasing student engagement. To successfully deal with these problems, a thoughtful and comprehensive approach is needed to support students and teaching staff in online learning environment.

Don State Technical University has successfully made the transition to online forms of course delivery thanks to the availability of online study options. A virtual learning environment "SKIF" enables students to have consistent learning experiences on the unified learning platform. Furthermore, "SKIF" implements functions to design courses, which allows teaching staff to place course materials online and collect daily assignments or homework in one place for tracking and grading. It helps teachers to get a better insight into student progress and accurately identify the struggling students. Learning materials are merged into a coherent whole, thus providing a clear path through the course material and helping students stay focused, as they do not switch between multiple apps and websites. When experiencing 
difficulties in using "SKIF" both teachers and students can rely on technical support services to handle support requests. Technical support has been critical to the success of the distance learning delivery mode at Don State Technical University in the early and ongoing stages of the COVID-19 epidemic.

The problem of adapting courses to a fully online environment inseparable from student engagement issues. When using the Zoom application for online class 'meetings', it is essential to create meaningful assignments that emphasise learning as a reflexive and participative process. By providing a unified environment that is engaging (Google Slides, Google Sheets) educators are able to maintain students' attention and match the assignments to course goals and learning objectives. It must also be admitted that transition to fully online learning requires extra workload handled by educators: additional effort must be devoted to create new types of assignments to promote active student engagement, educators will need to prepare for the delivery of effective feedback to reduce time loss, providing clear instructions is also critically important. It can be stated that educators need to ensure that assignments align with the distinctive features of a digital learning platform, or other digital tools. By carefully considering the assignments aimed at boosting student engagement educators are more likely to create a productive online learning environment and increase positive learning outcomes in higher education.

\section{References}

1. J. Butcher, J. Rose-Adams, Open Learning: The Journal of Open, Distance and e-Learning, 30, 127-137 (2015) doi:10.1080/02680513.2015.1055719

2. J. Umoh, E. Akpan, Journal of Education and Learning, 3, 60-70 (2014) doi:10.5539/jel.v3n4p60

3. N. Mohamed, F. Peerbhay, African journal of Health Professions Education, 4, 123-127 (2012) doi: 10.7196/AJHPE.179

4. Md. S. Khalid, M. J. L. Pedersen, Procedia - Social and Behavioral Sciences, 228, 614621 (2016) doi:10.1016/J.SBSPRO.2016.07.094

5. R. Davidson, Journal of Learning Design, 8, 94-105 (2015) doi: 10.5204/jld.v8i3.256

6. J. Little-Wiles, L. Naimi, Conflict Resolution \& Negotiation Journal, 4, 1- 13 (2011)

7. G. Thorsteinsson, Journal of Educational Technology, 10, 15-20 (2013)

8. S. W. Schmidt, C. M. Tschida, E. M. Hodge, Online Journal of Distance Learning Administration, 19, 1-10 (2016)

9. M. Bickle, R. Rucker, Journal of Online Higher Education, 4, 3-10 (2020)

10. S. Alharbi, S. Drew, International Journal of Advanced Computer Science and Applications, 5, 143-155 (2014) doi: 10.14569/IJACSA.2014.050120

11. J. T. Nagy, Education and Information Technologies, 21, 897-917 (2016) doi:10.1007/s10639-014-9360-6

12. W.-L. Shiau, P. Y. K. Chau, Information and Management, 53, 355-365 (2016) doi: 10.1016/j.im.2015.10.004

13. M. Jordan, D. Duckett, The Journal of Public and Professional Sociology, 10, 1-23 (2018)

14. F. Martin, D. U. Bolliger, Online Learning Journal, 22, 205-222 (2018) doi:10.24059/olj.v22i1.1092.

15. B. L. Hansen, E. Gray, Journal of Educators Online, 15, 24-44, (2018) doi:10.9743/jeo.2018.15.3.2 